Academic Platform Journal of Engineering and Science

journal homepage: http://apjes.com/

\title{
Soğuk İklim Bölgelerinde Bitki Topluluklarının Sıcaklık Etkileri: Erzurum Ata Botanik Bahçesi
}

\author{
${ }^{1}$ Sevgi Y1lmaz ${ }^{* 1}$ Mehmet Akif Irmak ${ }^{1}$ Emral Mutlu ${ }^{1}$ Hasan Yilmaz \\ ${ }^{1}$ Atatürk Üniversitesi, Mimarlık ve Tasarım Fakültesi, Peyzaj Mimarlığı Bölümü, Erzurum. \\ mairmak@atauni.edu.tr,
}

Günümüzde yapılmış olan birçok termal konfor çalışmasına bakıldığında; sıcak iklimlerde bitkilerin tek başlarına ya da topluluklar halinde serinletme etkileri araştıılmaktadır. Kış ayları için yapılan çalışmalarda ise bitkilerin 1sıtma etkisi daha çok önem arz etmektedir. Bitkilerin ısıtma etkisi kentlerde iklimi iyileştirirken aynı zamanda kentin ısınmasında da enerji tasarrufu sağlamaktadır. Yapılan çalışmalar bitkilerin aksine sert zeminlerin kışın serinletme etkisinin fazla, yazın ise daha sıcak olduğunu göstermektedir. Bu çalışmada, ekstrem kış kenti koşulları bulunan Erzurum'da Ata Botanik Bahçesindeki bitkilerin ve sert zeminin termal konfora etkisi araştıılmıştır. Yüzey sıcaklıkları 2017 kış ayları boyunca havanın açık olduğu farklı günlerde, saat 09:00, 13:00 ve 16:00 da hassas termal kamera ile görüntüler alınmıştır. Aynı zamanda, Sky-View Factor (SVF) ölçümleri ile sıcaklık ve nem değerleri de analiz edilmiştir. Kış aylarında Sarıçam (Pinus sylvestris L.) ile Huş (Betula alba $\mathrm{L}$.) toplulukları ve alandaki otoparktan alınan ölçümlerde en iyi termal konforu, ortalama $1.8^{\circ} \mathrm{C}$ daha sıcak çıkan Sarıçam (Pinus sylvestris L.) toplulukları sağlamıştır. Karla kaplı otoparkların yaydığı yüzey sıcaklığının diğerlerine göre ortalama $3.2^{\circ} \mathrm{C}$ daha serin çıktığı belirlenmiştir. Yapılan çalışma göstermiştir ki; sert geçen kış kentlerinde termal konforu sağlamak amaciyla ibreli ağaç korulukları oluşturulmalı ve geniş sert zeminler oluşturmaktan kaçınılmalıdır. Ayrıca doğal bitkilerin kentsel mekanda kullanılması termal konforlu, enerji tasarruflu ve ekolojik planlamalar için gereklidir.

Anahtar Kelimeler: Soğuk iklim, ssıtma etkileri, termal konfor, ağaçlar

\section{Heating Effects of Plant Communities in Cold Climate Regions: Erzurum Ata Botanic Garden}

\author{
${ }^{1}$ Sevgi Y1lmaz ${ }^{* 1}$ Mehmet Akif Irmak ${ }^{1}$ Emral Mutlu ${ }^{1}$ Hasan Y1lmaz \\ ${ }^{1}$ Atatürk University, Architectural and Design Faculty, Department of Landscape Architecture, Erzurum. \\ mairmak@atauni.edu.tr
}

\begin{abstract}
The heating effect of the plants is important for regulating thermal comfort in winter. The heating effect of the plants improves the climate in the cities and at the same time saves energy in the warming of the city. Studies indicate that hard floors in contrast to plants have more cooling effect in winter and warmer in summer. Plants also clean the intense polluted air in cities during winter months. The objective of this study was to determine the effect of thermal comfort of plants and hard floors in the Ata Botanical Garden in Erzurum. Substrate temperatures were taken at different times during the 2017 winter months at 09.00, 13.00 and 16.00 with a thermal camera. In addition, temperature and humidity values were measured with the Sky-View Factor (SVF) measurements at the same time. The results indicated that Scots pines (Pinus sylvestris L.) ensured the best thermal comfort with an average $1.8^{\circ} \mathrm{C}$ warmer surface as compared to the others; Birch (Betula alba L.) communities and the parking lot in the area. The average surface temperature of snow-covered parking lots was about $3.2{ }^{\circ} \mathrm{C}$ cooler than the others. The results of this study clearly indicated that the climate can be positively affected creating coniferous trees woodland with the aim of providing thermal comfort in the hard winter cities and the use of natural plants on urban space is necessary for thermal comfort ecological planning.
\end{abstract}

Keywords: Cold climate, heating effects, thermal comfort, trees.

*1 Sorumlu Yazar. Atatürk Üniversitesi, Mimarlık ve Tasarım Fakültesi, Peyzaj Mimarlığı Bölümü, Erzurum, mairmak@atauni.edu.tr, Tel:05424540459 


\section{GÍRIŞ̧}

Dünyanın temel 1sı kaynağı olan güneş, canlılığın temel unsurlarından biri olmanın yanında; yaşadığımız dış mekânların konforu üzerinde de etkili faktör olarak en başta gelmektedir. Güneşten yayılan ışınların gezegenimize ulaşarak atmosfer içerisinde bulunan taneciklere ve ardından yer yüzeyine çarpması ile 1sıya dönüşümü süreci güneş radyasyonu olarak adlandırılmaktadır. $\mathrm{Bu}$ süreç canlı yaşamının sürdürülmesi amacıyla gerekli olan ısının oluşturulmasının yanında, hidrolojik döngü, fotosentez ve diğer iklim parametreleri gibi faktörler üzerinde en etkili süreçtir. Yer yüzeyinin ne ile kaplı olduğu ise güneşten gelen 1şınların yansıması ve tutulması açısından oldukça önemlidir. Güneşten gelen ışınların yeryüzüne ulaşmasından sonra bir kısmı tutulmakta, bir kısmı ise yansıyarak atmosfere geri gönderilmektedir. Yeryüzünde bulunan materyallerin güneşten gelen 1sıyı tutarak, güneş kaybolduktan sonra çevresine bu ısıyı vermeleri olayına ise "karasal radyasyon" denilmektedir [1-2].

Yer yüzeyi üzerindeki 1sı tutma potansiyeli yüksek olan sert zeminlerdeki artış, karasal radyasyonun artmasına neden olurken; bu durum kentsel 1sı adası oluşumuna sebep olan faktörlerin başında gelmektedir.

Kentsel mekânlarda dış mekân kullanımını sağlayan teraslar, kaldırımlar ve otopark gibi alanları oluşturan sert zemin yüzey kaplamaları üzerinde oldukça fazla çalışmalar yapılmaktadır. $\mathrm{Bu}$ alanların özellikle kentsel 1s1 adas1 oluşumu üzerine etkileri vurgulanmakta ve genelde sicak kentler ya da sıcak yaz dönemleri üzerinde durulmaktadır [34-5].

Birleşmiş Milletler'in 2016 yılı Dünya Şehirleşme Raporlarına göre dünya nüfusunun $\% 54.5$ 'i kentlerde yaşamakta olup, bu oranın 2030 yılına kadar \%60'a ulaşması beklenmektedir [6]. Kentsel alanlardaki nüfus artışına paralel olarak kentsel mekânlarda yaşanan yoğun yapılaşma, yeşil ve açık alanların azalması, termal konforlu mekânların azalmasına yol açmaktadır. Kentsel mekânda diş ortamlarda termal konforu etkileyen canlı ve cansız materyaller üzerinde sürekli çalışmalar yapılmaktadır. Termal konforu olumlu yönde etkileyen ağaç türleri, yoğunlukları ve çeşitliliği gibi konularda oldukça fazla çalışmalar yapılmaktadır [7-8-9-1011-12].Özellikle ağaçların dal ve yaprakları ile güneş radyasyonunu hafiflettikleri ve buharlaşma ile 1S1 akışını artırarak ortamı serinlettikleri vurgulanmaktadır [10-13].

Kentsel dış mekânda yapılan çalışmalarda yeşil alanların sayısız yararlarının yanında, termal konforu ve kent mikro klimasını olumlu etkilediği belirlenmiştir. Yapılan çalışmalarda yeşil alanlarındaki termal konforun kentsel mekâna göre daha iyi olduğu vurgulanmaktadır [14-15].

Yeşil alanlar ve özellikle ağaçlık alanlar, güneşten gelen özellikle kısa dalga boylu radyasyonun büyük bir kısmını kendisi absorbe ettiğinden yaz dönemlerinde atmosferin aşırı ısınmasını kısmen engellerler [16].
Bitkiler özellikle terleme, güneş 1şıklarını yansıtma, 1sı tutma, gölgeleme ve rüzgârın azaltılması veya yönlendirilmesi gibi fonksiyonları ile mikro iklime katkı yaptıkları bilinmektedir. Bitkiler, terleme için ihtiyaç duydukları enerjiyi büyük ölçüde çevresindeki havadan alır ve bu bitki çevresinde daha serin bir alan oluşmasına katkı sağlarlar. Güneşten gelen ışının enerjisi cisimlere çarptığında 1sıya dönüşmektedir. Bitki güneşten gelen bu 1şınların bir kısmını yansıtmakta ve böylece 1sıya dönüşmeden atmosfere göndermektedir. Bir kısmını ise yaprak ve dal yüzeyinde tutmaktadır. Bu yolla gölgeleme sağlanmakta ve bitki alt kısımları serin kalmaktadır. Bitkilerin yaprakları vasıtası ile mikro iklime etkileri Şekil 1'de görülmektedir. Bitkilerin rüzgâr azaltma ve yönlendirme özellikleri de kentsel mikro iklim üzerinde olumlu veya olumsuz etkilere sebep olabilmektedir. Yoğun kullanıldıklarında rüzgâr hızının azalması sıcaklık artışına sebep olurken, planlı olarak yapılan ve rüzgâr koridoru şeklinde tasarlanan ağaçlar sıcak iklimli kentlerde veya sıcak dönemlerde termal konforu olumlu etkilemektedir [17-18].

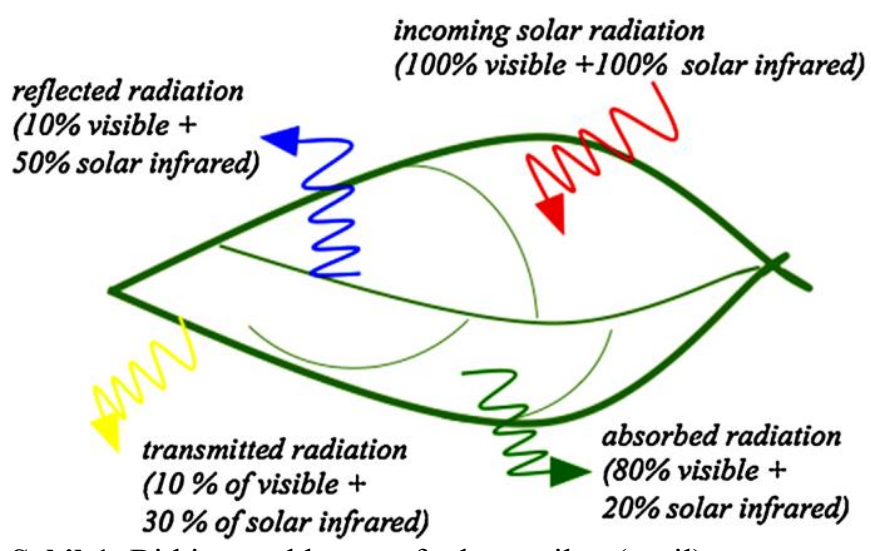

Şekil 1. Bitki yaprakları tarafından emilen (yeşil), yansıyan (mavi) ve iletilen (sarı) güneş 1şınları [18].

Günümüzde bitkilerin kentlerdeki fonksiyonları incelenirken soğuk kentlerde veya kış dönemlerindeki mikro klimatik etkileri ile ilgili çalışmalar istenilen seviyelerde değildir. Özellikle karla kaplı yüzeylerde güneş radyasyonu ve karasal radyasyonun durumu, bitkilerin karla kaplı dönemlerdeki mikro iklim fonksiyonları gibi konuların daha fazla araştırılması, kış kentleri açısından önem taşımaktadır.

Erzurum kenti de iklim koşullarının yaşam şartlarını olumsuz etkilediği kentlerden biri olarak dikkat çekmektedir. Yapılan bu çalışma ile soğuk ve uzun geçen kış koşullarının kentsel alanlarda yaşayan halk için oluşturduğu olumsuzlukların giderilmesi, kentsel mikro klima alanlarının sağlanması bakımından yapılabilecekler için yol gösterici olması hedeflenmiştir. Çalışmada dış mekânda termal konforu belirlemek için termal kamera kullanımı [8,19-20] ve kullanılan bitkilerde Gökyüzü Görünürlük Oranı (SVF) [7-10-21] gibi ölçümler yapılarak karla kaplı yüzeylerde bitkilerin rolü belirlenmiştir. 


\section{MALZEME VE YÖNTEM}

Çalışma Türkiye'nin doğusunda bulunan Erzurum kentinde yürütülmüştür. Kent kış dönemlerinde $-37^{\circ} \mathrm{C}$ ye varan düşük sıcaklıkları ile ülkenin en soğuk kentlerinden biri olarak dikkat çekmektedir. Yaklaşık 1850 m rakımda kurulu olan kent ve çevresinde karın yerde kalma süresi yıllık 113 gün ortalamasına sahiptir. Kış dönemleri ağır şartlara sahip olan kentte yaz dönemleri ise sicak ve kurak geçmekte, zaman zaman $36^{\circ} \mathrm{C}$ 'lere varan sıcaklıklar da görülebilmektedir.

Çalışma kapsamında ölçümler, kent merkezinde bulunan 35 hektar büyüklükteki Ata Botanik Bahçesinden alınmıştır. Özellikle kış aylarında dış mekân konforunu elde etmek için analizler yapılmıştır. Bu amaçla 2017 yılı kış ayında, Ata Botanik Bahçesinin çevresindeki yüksek bir yapıdan yüksek çözünürlüklü termal kamera ölçümleri alınmıştır. Görüntü kayıtlarında Optris ${ }^{\circledR}$ PI-450 (Optris, Berlin, Germany) marka yüksek hassasiyetli termal kamera kullanılmıştır. $\mathrm{Bu}$ görüntüler saat 09:00, 13:00 ve 16:00 da alınmış ve kaydedilmiştir. Aynı ölçüm saatlerinde ortamın sıcaklığı $\left({ }^{\circ} \mathrm{C}\right)$ ve nem (\%) değerleri de ölçülmüştür. Termal kamera ölçümü yapılan alanda bulunan ağaçların altında, fotoğraf makinasına takılan balık gözü lensle çekimler yapılmış ve bu ağaçların gökyüzü görünürlük oranı (Sky View Factor=SVF) belirlenmiştir. Çalışma alanının konum haritası Şekil 2'de verilmiştir.

Gökyüzü görünürlük oranı (SVF) tamamen kapalı ve tamamen açık olduğunu gösteren 0 ile 1 arasında değer alır. Rakam 1'e yaklaştıkça gökyüzü görünürlüğü artarken, 0'a yaklaştığında ise görünürlük oranı düşmektedir [22].

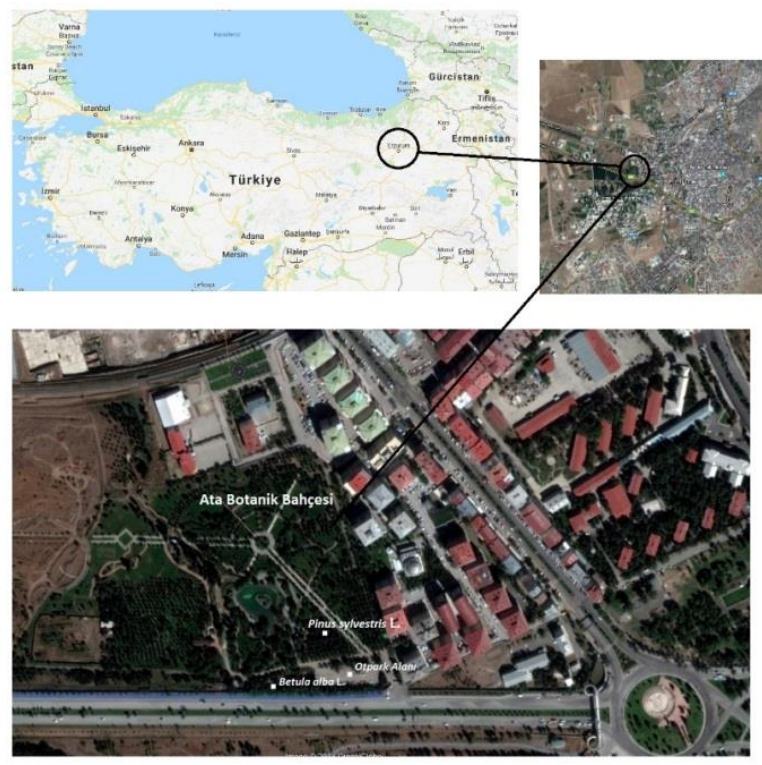

Şekil 2. Çalışma alanı konum haritası.

\section{BULGULAR}

Çalışma kapsamında yapılan ölçümler kış dönemlerinde ve yer yüzeyinin karla kaplı olduğu dönemde yapılmıştır. Kış dönemlerinde botanik bahçesinin kapalı veya kullanılmıyor olmasından dolayı gerek otopark yüzeyi ve gerekse ağaç altları ölçüm yapılan dönemde yaklaşık $40 \mathrm{~cm}$ kar örtüsü ile kaplı durumdadır.

Bitkilerden alınan SVF görüntüleri ise bitkilerin alt kısmına ulaşan ve buradan yansıyan 1şıklar açısından, yaprak ve dal sıklığına bağlı olarak bitkinin yüzeyinde absorbe ettiği 1S1 açısından ve ibreli-geniş yapraklı bitkilerde 1S1 absorbsiyonunun tespiti açısından önem taşımaktadır.

Kış döneminde yapılan ölçümlere göre, Pinus sylvestris L. (Sarıçam) bitkisi için SVF değeri 0.043 olurken, bu değer Betula alba L. (Huş) bitkisi için 0.167 olarak belirlenmiştir (Şekil 3).

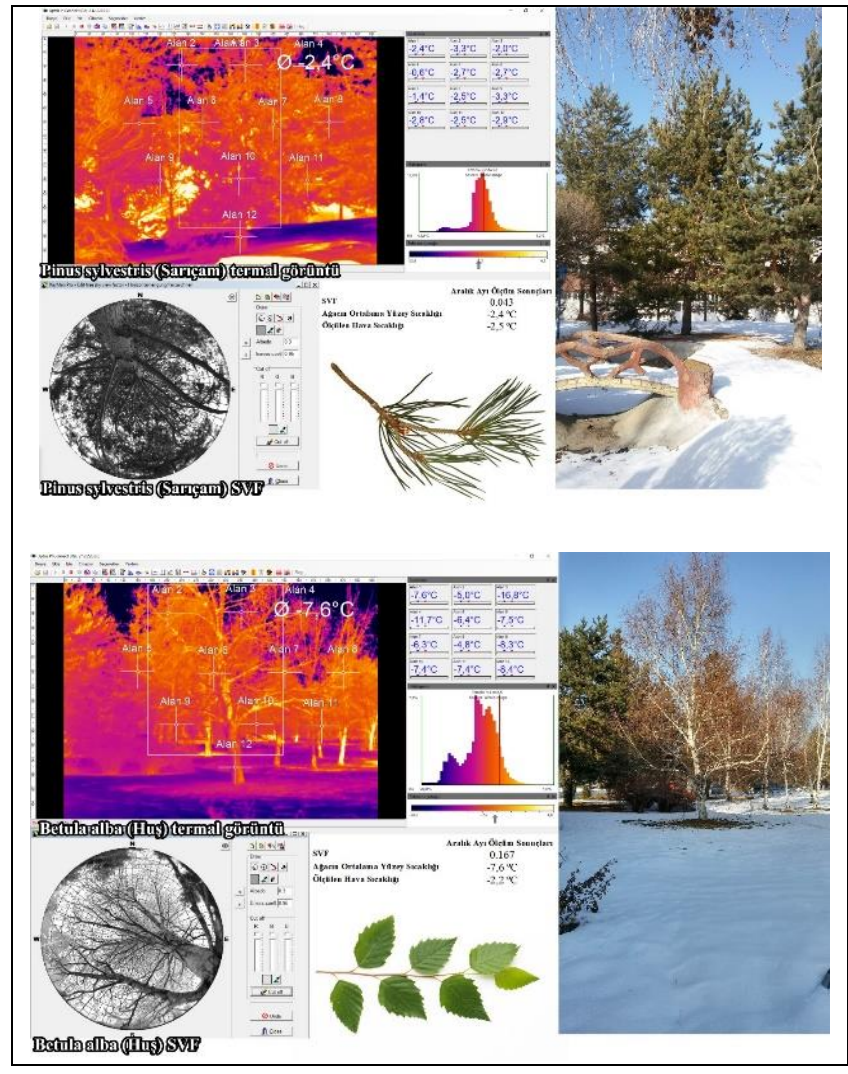

Şekil 3. Kış dönemlerinde Pinus sylvestris L. (Sarıçam) ve Betula alba L. (Huş) bitkileri için SVF (Sky View Factor=Gökyüzü Görünürlük Oranı) değerleri.

Çalışma kapsamında yüksek çözünürlüklü termal kamera ile yapılan ölçümler saat $09.00, \quad 13.00$ ve 16.00 'da gerçekleştirilmiştir. Termal kamera, güneşten gelip yeryüzüne çarparak ısıya dönüşen yüzeylerde sıcaklık tespiti yapmakta olup; bu amaçla sarıçam ve huş koruluklarının bitki taç yüzeyleri ile üzeri karla kaplı bir otoparkın yüzey sıcaklıkları değerlendirilmiştir. Bu şekilde yıllık 113 gün ortalama karla kaplı gün sayısına sahip olan Erzurum kentinde karla kaplı dönemlerde, kışın yapraklı (Pinus sylvestris L.) ve yaprak döken (Betula alba L.) bitkilerinin etkileri termal konfora belirlenmeye çalışılmıştır. Yapılan ölçümlere ilişkin veriler Tablo 1'de görülürken; üç farklı 
saatte alınan termal kamera görüntüleri ise Şekil 4, Şekil 5 ve Şekil 6'da verilmiştir.

Tablo 1. Çalışma alanlarının yüzey sıcaklıkları.

\begin{tabular}{lcccc}
\hline & $\begin{array}{c}\mathbf{0 9 . 0 0} \\
\left({ }^{\circ} \mathbf{C}\right)\end{array}$ & $\begin{array}{c}\mathbf{1 3 . 0 0} \\
\left({ }^{\circ} \mathbf{C}\right)\end{array}$ & $\begin{array}{c}\mathbf{1 6 . 0 0} \\
\left({ }^{\circ} \mathbf{C}\right)\end{array}$ & $\begin{array}{c}\text { Ortalama } \\
\left({ }^{\circ} \mathbf{C}\right)\end{array}$ \\
\hline $\begin{array}{l}\text { Otopark } \\
\begin{array}{l}\text { Alanı } \\
\text { Betula alba }\end{array}\end{array}$ & -11.9 & -10.9 & -7.2 & -10.0 \\
$\begin{array}{l}\text { koruluğu } \\
\text { Pinus } \\
\text { sylvestris } \\
\text { koruluğu }\end{array}$ & -8.1 & -7.3 & -4.1 & -6.5 \\
\hline
\end{tabular}

Termal kamera ile alınan yüzey sıcaklıklarının 09.00, 13.00 ve 16.00 saatlerindeki ortalamaları incelendiğinde karla kaplı otopark alanında yüzey sıcaklığının $-10.0{ }^{\circ} \mathrm{C}$ 'ye kadar düştüğü, sarıçam koruluğu yüzeyinin ortalama $-6.1{ }^{\circ} \mathrm{C}$ 'ye kadar ısınabildiği ve yapraksız olan huş koruluğunun da -6.5 ${ }^{\circ} \mathrm{C}$ sıcaklık gösterdiği tespit edilmiştir (Tablo 1).

Güneşin 1sıtma etkisinin zayıf olduğu sabah saatlerinde otopark alanı üzerinde ölçülen sıcaklık oldukça düşük çıkarken; bu değer $-11.9{ }^{\circ} \mathrm{C}$ 'ye ulaşmıştır. Aynı saatte sarıçamlar üzerinde ölçülen sıcaklık $\quad-7.9{ }^{\circ} \mathrm{C}$ olarak ölçülmüştür. Otopark alanı ile sarıçam yüzeyleri arasında $4.0^{\circ} \mathrm{C}$ sıcaklık farkı oluşurken bu değer otopark ile huş yüzeyleri arasında $3.8^{\circ} \mathrm{C}$ olarak ölçülmüştür (Şekil 4).

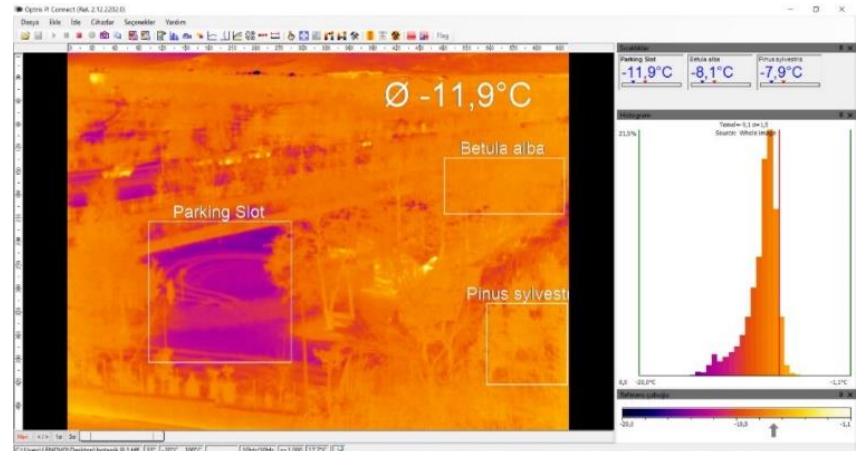

Şekil 4. Saat 09.00 için termal kamera analizi.

Saat 13.00'da otopark alanı üzerinde ölçülen sıcaklık -10.9 ${ }^{\circ} \mathrm{C}$ olarak ölçülmüştür. Öğlen saatlerinde güneşin etkisini artırması ile birlikte otopark yüzeyindeki sıcaklık da $1.0^{\circ} \mathrm{C}$ artmıştır. Aynı saatte sarıçamlar üzerinde ölçülen sıcaklık $6.8^{\circ} \mathrm{C}$ olarak ölçülmüştür. Huş yüzeyleri üzerindeki sıcaklık ise $-7.3^{\circ} \mathrm{C}$ olarak ölçülmüştür (Şekil 5).

Güneşin 1sıtma etkisinin yüksek olduğu ve yüzeyleri 1sıttığı bir saat olan 16.00 'da ise otopark yüzeyindeki sıcaklık değeri -7.2 ${ }^{\circ} \mathrm{C}$ 'ye kadar yükselerek gün içerisindeki en yüksek değere ulaşmıştır. Benzer şekilde sarıçam yüzeyleri de en yüksek sıcaklık değerine ulaşarak $-3.8^{\circ} \mathrm{C}$ 'ye çıkmıştır. Huş yüzeyleri ise $-4.1{ }^{\circ} \mathrm{C}$ 'ye kadar yükselmiştir. Otopark alanı ile çam yüzeyleri arasındaki sıcaklık farkı ise $3.4{ }^{\circ} \mathrm{C}$ olarak ölçülmüştür (Şekil 6).

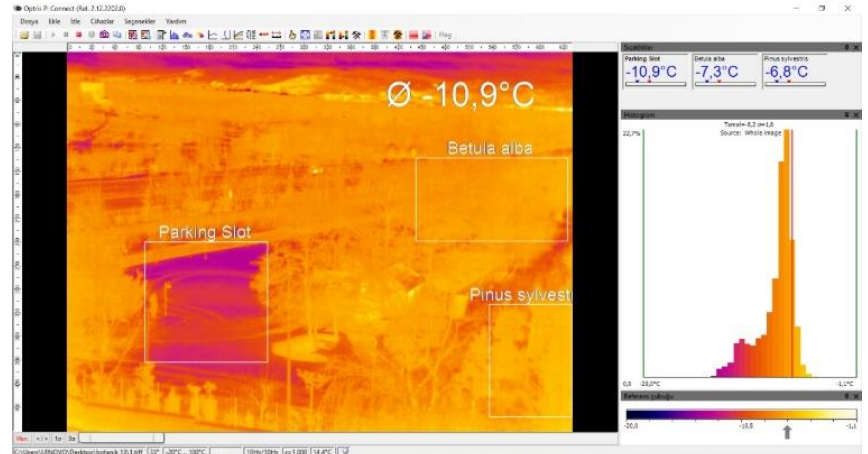

Şekil 5. Saat 13.00 için termal kamera analizi.

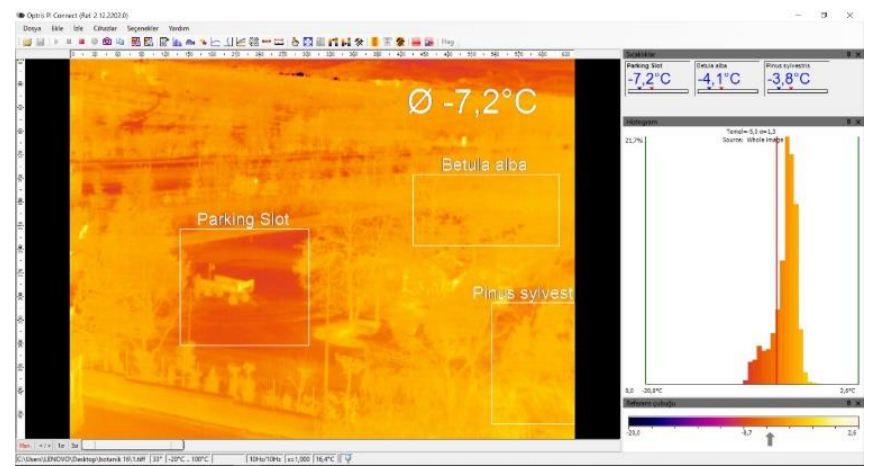

Şekil 6. Saat 16.00 için termal kamera analizi.

Çalışma kapsamında elde edilen yüzey sıcaklıklarının grafik gösterimlerinin yer aldığı Şekil 7. İncelendiğinde; sarıçam yüzey sıcaklıklarının tüm saatlerde diğer yüzeylere göre daha sıcak olduğu ve güneşe maruz kalmasına rağmen karla kaplı açık-yeşil alanların ağaçlık alanlara göre daha soğuk değerlere sahip olduğu görülmektedir.

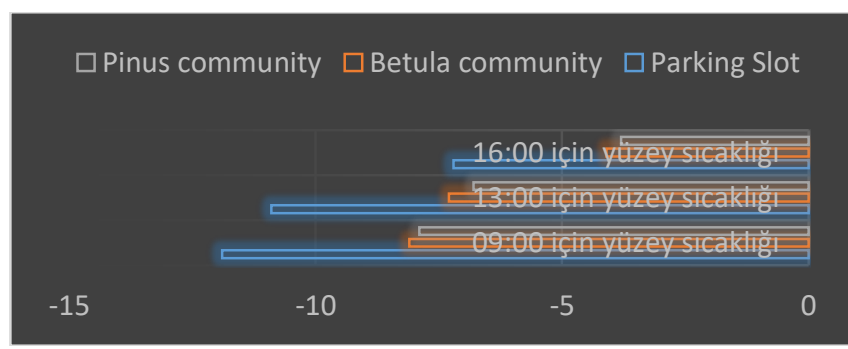

Şekil 7. Çalışma alanlarının yüzey sıcaklıkları için grafik gösterimleri

\section{DEĞERLENDİRME VE SONUÇ}

Kent termal konforunu ve mikro iklimini araştırmak amacıyla dünyanın farklı iklim bölgelerinde birçok çalışmalar yapılmıştır [23-24-25-26-27-28-29]. Bu çalışmalarda genel olarak kentsel 1S1 adası üzerinde durulmuştur. Soğuk iklim koşullarına sahip ve kar örtüsünün uzun süre kaldığı kentlerde güneş radyasyonu dramatik bir şekilde azalmakta, güneş 1şınlarının kar örtüsüne çarparak atmosfere geri dönmesi sonucunda kent mikro iklimi değişimler yaşamaktadır. Meydana gelen albedo, kentsel alanlarda termal konfor üzerinde olumsuzluklara neden olmaktadır. 
Kış dönemlerinde, kar örtüsü atmosfer ile yer yüzeyi arasında gerçekleşen ısı ve nem değişimleri üzerinde önemli bir rol oynamaktadır [23]. Walsh ve ark. [30], çalışmalarında, kar örtüsünün ABD genelinde aylık sıcaklıktaki değişimin yaklaşık \% 10-20'sini oluşturduğunu belirlemişlerdir.

Zhang ve ark. [31], çalışmalarında bitki örtüsünün gerek k1ş dönemlerinde ve gerekse yaz dönemlerinde, dış mekân termal konforu üzerinde etkili olduğunu belirtmişlerdir. Çalışmalarında bitki örtüsünün yaz dönemlerinde konfor üzerinde olumlu etkiler sağladığını, kış dönemlerinde ise özellikle yaprak dökmeyen ağaçların gölge etkisinden dolayı termal konfor üzerinde olumsuz etkilere sahip olduğunu ifade etmişlerdir. Ancak yapılan bu çalışmada yeryüzünün karla kaplı olmaması nedeniyle, ağaçlar yer yüzeyine ulaşacak 1şık miktarını azaltmakta ve bu da yer yüzeyinde tutulabilecek 1sı miktarını düşürmektedir.

Yapılan bu çalışma kapsamında ağaç yüzeylerinin kar ötüşünü tutmaması nedeniyle güneşten gelen 1şınların çarpması sonucu bir kısmının ısıya dönüşerek, karla kaplı zeminlere göre daha sıcak oldukları tespit edilmiştir.

Normal koşullar altında kaplı yüzeylerden oluşan otopark alanlarının güneş etkisi ile 1s1 absorbe etmesi ve kentsel 1s1 adası oluşumuna katkı vermesi beklenmektedir. Ancak bu çalışma kapsamında yapılan ölçümler göstermektedir ki; karla kaplı olan otopark alanında güneş ışınlarının albedo sonrasında atmosfere geri dönmesi ile bu alanda ölçülen yüzey sıcaklıkları $-11.9^{\circ} \mathrm{C}$ 'ye kadar düşmüştür.

Yaprak döken bir ağaç olan Betula alba L. (Huş) bitkisi koruluğunda kış dönemlerinde alınan termal görüntüler incelendiğinde, güneşten gelen 1sıyı absorbe yeteneğinin, yaprak dökmeyen Pinus sylvestris L. (Sarıçam) ağacına göre düşük olduğu görülmüştür. Bu kapsamda ağaçlardan alınan SVF değerlerinin de önemi görülmektedir. Daha sık, kompakt dal ve yaprak yapısına sahip olan ve yaprak dökmeyen sarıçamların 0.043 gibi düşük bir SVF değerine sahip olduğu, kapalılık oranı daha az olan ve yaprak döken Huş ağaçlarının 0.167 SVF değerine sahip olduğu görülmektedir. Yaprak ve dal sıklığı arttıkça SVF düşmektedir. Yaprak ve dal sıklığındaki artış ise güneşten gelen ışınların çarparak yansımadan büyük çoğunluğunun 1sıya dönüşmesine neden olmaktadır. Yapılan bu çalışma kapsamında da elde edilen sonuçlar bu durumu desteklemektedir.

Kar örtüsünün uzun süre yerde kaldığı ve kış şartlarının zorlu geçtiği soğuk kentlerde, güneş ışınlarının yerde bulunan kar yüzeyleri tarafindan yansitılması ve atmosfere geri gönderilmesi, ortamın soğumasına, bu da yaşam konforunun düşmesine neden olmaktadır. Kış dönemlerinde kar örtüsünün yoğun bir çaba ile temizlenmesi ve kentten uzaklaştırılması durumunda albedosu kar örtüsüne göre çok daha düşük olan asfalt, beton, kaplı kaldırımlar, yeşil yüzeyler ve benzeri kentsel kaplama yüzeyleri tekrar 1sınmaya başlamakta ve kar örtüsünün temizlenmediği kent çevresindeki kırsal alanlara göre daha sıcak olmaktadır. Bu durum Erzurum kenti ile komşu olan Erzincan ilinde Toy ve Yılmaz [32] tarafindan yapılan bir çalışmada değerlendirilmiştir. Yaklaşık 10 yıllık iklim verilerinin değerlendirildiği çalışma sonucunda; Erzincan gibi kırsal alanları kış dönemlerinde karla kaplı bir kentte, kentsel alanların daha konforlu olduğu sonucuna ulaşılmıştır.

Karla kaplı gün sayısı ortalamasının yıllık 113 gün olduğu Erzurum kentinde yapılan bu çalışma kapsamında yaprak dökmeyen bir ağaç olan Sarıçamdan oluşan korulukların ağaç taç yüzeylerinde, otopark gibi açık alanlardan ve yaprak döken huşlardan oluşan koruluklardan daha fazla 1s1 tuttukları belirlenmiştir. Bu nedenle Erzurum gibi soğuk ve karın yerde kalma süresi uzun olan kentlerde Sarıçam gibi yaprak dökmeyen bitkilerden oluşan korulukların yapılması, kış kentinde albedoyu düşürmekte, bu da kent mikro kliması üzerinde olumlu etkilere sebep olmaktadır.

\section{TEŞEKKÜR}

Bu çalışma TÜBİTAK tarafindan desteklenen 2150627 nolu 1001 projesi kapsamında alınan alet ve ekipmanlar kullanılarak yapılmıştır.*Bu çalışma ISEM 2018 sempozyumunda "Soğuk İklim Bölgelerinde Bitki Topluluklarının Sicaklık Etkileri: Erzurum Ata Botanik Bahçesi" başlıklı bildiri olarak sunulan çalışmadan geliştirilerek hazırlanmıştır.

\section{KAYNAKÇA}

[1] Çepel N. Peyzaj Ekolojisi Ders Kitab1. İstanbul Üniversitesi Yayın No:3510, 1988. 215s.

[2] Şarlak N., Güven A. Global güneş radyasyon tahmini: Gaziantep uygulaması. 2016. İMO Teknik Dergi, 75617568.

[3] Jongtanom Y., Kositanont C., and Baulert S. Temporal variations of urban heat island intensity in three major cities, Thailand.. Mod. Appl. Sci. 2011, 5 (5), 105-110.

[4] Correa EN, Ruiz MA, Cantón A, and Lesino G. Thermal comfort in forested urban canyons of low building density. An assessment for the city of Mendoza. Build. Environ. 2012, 58:219-230

[5] Irmak MA., Yilmaz S., and Dursun D., Effect of different pavements on human thermal comfort conditions. Atmosfera 2017, 30(4), 355- 366, DOI:10.20937/ATM.2017.30.04.06

[6] Anonymous. United Nations, The World's Cities, Economics and Social Affairs Data Booklet. 2016, 29p.

[7] Ng E., Chen L., Wang Y., and Yuan C. A study on the cooling effects of greeningin a high-density city: an experience from Hong Kong. Build. Environ. 2012, 47,256271.

[8] Aguiar AC., French K., and Chisholm LA. A comparison of the ameliorating effects of native and exotic street trees on surface heat retention at dusk. Urban Climate 2014, 10 (2014) 56-62. 
[9] Lee H., Mayer H., and Chen L. Contribution of trees and grasslands to themitigation of human heat stress in a residential district of Freiburg, SouthwestGermany. Landscape and Urban Planning, 2016, 148, 37-50.

[10] Kong FH., Yan WJ., Zheng G., Yin HW., Cavan G., Zhan WF., Zhang N., and Cheng L.. Retrieval of threedimensional tree canopy and shade using terrestrial laser scanning (TLS) data to analyze the cooling effect of vegetation Agric. For. Meteorol., 2016, 217: 22-34.

[11] Yilmaz S., Mutlu E., Yılmaz H., 2018. Alternative Scenarios For Ecological Urbanizations Using ENVI-Met Model. Environmental Science and Pollution Research, 25 (26): 26307-26321.

[12] Irmak MA., Yilmaz S., Mutlu E., and Yilmaz H. Assessment of the effects of different tree species on urban microclimate. Environmental Science and Pollution Research, 2018, https://doi.org/10.1007/s11356-018-1697-8 in press.

[13] Thom JK., Coutts AM., Broadbent AM., and Tapper NJ. The influence of increasing tree cover on mean radiant temperature across a mixed development suburb in Adelaide, Australia. Urban For. Urban Green., 2016, 20: 233- 242.

[14] Shashua-Bar L., and Hoffman ME. Vegetation as a climatic component in the design of an urban street: an empirical model for predicting the cooling effect of urban green areas with trees Energy Build., 2000, 31 (3): 221-235. [15] Hendel M., Azos-Diaz K., and Tremeac B. Behavioral adaptation to heat-related health risks in cities Energy Build, 2017, 152: 823-829.

[16] Kayhan M. Küresel İklim Değişikliği ve Türkiye. Küresel İklim Değişikliği Kongresi, 2007.

[17] Hsieh CM, Jan FC, and Zhang L. A simplified assessment of how tree allocation, wind environment, and shading affect human comfort. Urban Forestry Urban Greening 2016, 18:126-137.

[18] Kong L, Lau KKL, Yuan C, Chen Y, Xu Y, Ren C, and $\mathrm{Ng}$ E. Regulation of outdoor thermal comfort by trees in Hong Kong. Sustainable Cities Soc. 2017, 31:12-25.

[19] Ginner S, Vogt J, Tharang A, Dettmann S, and Roloff A. Role of street trees in mitigating effects of heat and drought at highly sealed urban sites. Landscape and Urban Planning, 143, 33-42. doi:10.1016/j. landurbplan. 2015, 2015.06.005

[20] Aubrecht DM, Helliker BR, Goulden ML, Roberts DA, Still CJ, and Richardson AD. Continuous, long-term, highfrequency thermal imaging of vegetation: Uncertainties and recommended best practices.Agricultural and Forest Meteorology, 2016, 228, 315-326. doi:10.1016/j.agrformet.2016.07.017.

[21] Tan Z, Lau K K L, and Ng E. Planning strategies for roadside tree planting and outdoor comfort enhancement in subtropical high-density urban areas. Building and Environment, 2017, 120, 93-109.

[22] De Souza LCL. Thermal environment as a parameter for urban planning. Energy Sustainable Dev. 2007, 11(4):44-53. [23] Shui T, Liu J, Zhang P, Liu S, and Zhao Z. Development of an urban canopy model for the evaluation of urban thermal climate with snow cover in severe cold regions. Building and Environment, 2016, 95, 160-170.

[24] Busato F, Lazzarin RM, and Noro M. Three years of study of the Urban Heat Island in Padua: Experimental results. Sustainable Cities and Society, 2014, 10, 251-258.

[25] Chun B., and Guldmann, JM. Spatial statistical analysis and simulation of the urban heat island in high-density central cities, Landsc. Urban Plan. 2014, 125, 76-88.

[26] Pandey P, Kumar D, Prakash A, Masih J, Singh M, Kumar S, and Kumar K. A study of urban heat island and its association with particulate matter during winter months over Delhi. Science of the Total Environment, 2012, 414, 494-507.

[27] Li YY., Zhang H, and Kainz W. Monitoring patterns of urban heat islands of the fast-growing Shanghai metropolis, China: using time-series of Landsat TM/ ETMş data, Int. J. Appl. Earth Observat. Geoinformat. 2012, 19, 127-138.

[28] Kolokotroni M, and Giridharan R. Urban heat island intensity in London: an investigation of the impact of physical characteristics on changes in outdoor air temperature during summer, Sol. Energy 2008, 82, 986-998. [29] Lokoshchenko MA. Urban 'heat island' in Moscow, Urban Clim. 2014, 10, 550-562.

[30] Walsh JE, Tucek D R., and Peterson MR. Seasonal snow cover and short-term climatic fluctuations over the United States. Monthly Weather Review, 1982, 110(10), 1474-1486. [31] Zhang L, Zhan Q, and Lan Y. Effects of the tree distribution and species on outdoor environment conditions in a hot summer and cold winter zone: A case study in Wuhan residential quarters. Building and Environment, 2018, 130, 27-39.

[32] Toy S, and Yilmaz S. Evaluation of urban-rural bioclimatic comfort differences over a ten-year period in the sample of Erzincan city reconstructed after a heavy earthquake. Atmósfera, 2010, 23(4), 387-402. 